\title{
Uma Análise Neoriemanniana da Primeira Cena do Artémis de Nepomuceno
}

\author{
A Neo-Riemannian Analysis of Nepomuceno's \\ Artémis' First Scene
}

\author{
Rita de Cássia Taddei \\ taddei.rita@gmail.com
}

Resumo: Da extensa obra teórica de Hugo Riemann, sua teoria das funções harmônicas permanece sendo a contribuição mais difundida. Menos conhecidos, os escritos da última fase sugerem novos modelos de compreensão do campo harmônico tonal que abandonam os paradigmas funcionalistas. Desde as últimas décadas do século XX, esse testamento de Riemann tem sido reavaliado por uma nova geração de teóricos, denominados neo-riemannianos, dentre os quais se destacam Lewin, Hyer, Richard Cohn e David Kopp, que propuseram suas próprias teorias a partir do modelo de Riemann. O foco deste trabalhoé fazer uma breve consolidação da teoria da harmonia transformacional neo-riemanniana, adotando finalmente o modelo proposto por David Kopp (2002) para apresentar uma análise transformacional da Cena I da ópera Artémis de Alberto Nepomuceno.

Palavras-chave: teoria transformacional neoriemanniana, Tonnetze, dualismo harmônico, harmonia cromática, música brasileira, Alberto Nepomuceno.

\begin{abstract}
From the lengthy theoretical work of Hugo Riemann, his theory of harmonic function continues to be his most known contribution. Less spread out, the writings of his last phase suggest new models for understanding the tonal harmonic field that abandon the functional paradigms. Since the last decades of the XXth Century, Riemann's testamen thas been reevaluated by a new generation of music theorists, called neo-riemannians, among which we can highlight Lewin, Hyer, Richard Cohn and David Kopp, who have proposed their own theories after Riemann's model. The focus of this paper is to resume the original steps of the neoriemannian transformational harmonic theory, adopting finally the model proposed by David Kopp (2002) to present a transformational analysis of the first scene of Alberto Nepomuceno's opera Artémis.
\end{abstract}

Keywords: neoriemannian transformational theory, Tonnetze, harmonic dualism, chromatic harmony, Brazilian music, Alberto Nepomuceno. 


\section{Introdução}

Autor de cerca de oitenta escritos sobre pedagogia, história e teoria da música, Hugo Riemann é, por certo, uma referência sobre estes assuntos, embora tenha ficado mais conhecido pelos seus estudos sobre o sistema tonal.

Neste trabalho, abordamos uma parte da teoria de Riemann, a que trata das relações entre as fundamentais dos acordes associadas à questão do dualismo harmônico, com uma explicação sobre as marchas e câmbios da harmonia, termos usados por Riemann para designar as várias progressões entre os acordes.

Com base na teoria riemanniana, que sistematiza as relações harmônicas orientando-se pelos intervalos entre as fundamentais dos acordes alterados, teóricos organizaram novos sistemas de classificação para essas mesmas relações intervalares, dando, assim, uma nova perspectiva à ferramenta analítica de Riemann. Essas teorias são denominadas neo-riemannianas, uma vez que têm como base as colocações de Riemann sobre as conexões do sistema harmônico.

Esses sistemas, organizados pelos neo-riemannianos, compreendem uma reformulação dessas relações, propondo um novo modo de notação, mais facilmente compreensível e, consequentemente, adequado a trabalhos de análise.

Para orientar a abordagem sobre as relações intervalares entre os acordes, ressaltando-se as relações de terças cromáticas na teoria de Riemann, consideramos conveniente apresentar inicialmente as propostas de três teóricos anteriores sobre a mesma questão, a partir dos quais Riemann desenvolveu sua teoria, examinando noções e conexões em geral do sistema harmônico e suas relações com questões específicas das relações de terça.

Esta discussão começa com Rameau, que, no século XVIII, articulou um lugar para as relações de terça no sistema tonal. O problema continuou a ser estudado no século XIX, com Reicha e Weber que avançaram outras noções sobre as relações de terça, chegando-se então a Riemann, que criou uma complexa teoria da tonalidade cromática.

\section{As teorias de Rameau, Reicha e Weber}

Na medida em que, para as tonalidades maiores, os acordes I e vi assumem funções no campo da tônica, IV e ii da subdominante e $\mathrm{V}$ e vii ${ }^{\circ}$ da dominante, restava considerar o acorde iii, sobre o grau da mediante, que desde Rameau ofereceu maior dificuldade para ser encaixado na teoria da harmonia tonal. Quanto ao modo menor, i e III assumem funções do campo da tônica, iv e ii ${ }^{06}$ da subdominante, v, V, VII e vii ${ }^{\circ}$ da dominante, restando, portanto, esclarecer a função de VI, sobre o grau da sub-mediante. Entretanto o problema para a teoria complicou-se ainda mais quando compositores como Beethoven e Schubert 
passaram a usar sistematicamente mediantes alteradas cromaticamente, e não apenas como dominantes secundárias. Kopp (2002) apresenta uma perspectiva detalhada da evolução das teorias sobre a harmonia cromática que nos serviu de roteiro para as considerações seguintes.

Rameau, Reicha e Weber apresentaram argumentos para a ocorrência de relações diretas de mediantes cromáticas, e relações próximas e distantes de acordes dentro de uma tonalidade, apontando a coerência dessas relações. No século XIX, as relações de mediantes cromáticas se tornaram mais frequentes na música, ao mesmo tempo em que as teorias de relações tonais vinham se tornando mais complexas e sistemáticas.

Na teoria de Rameau, relações de terça cromática desempenhavam um papel relativamente pequeno, enquanto relações de mediantes diatônicas eram comuns, e suas progressões significavam uma sucessão de duas tônicas proximamente relacionadas. Progressões de mediante diatônica podiam ser vistas, segundo o teórico, em dois contextos. O primeiro seria dentro de um sistema de proporções, no qual quintuplicar a proporção da quinta perfeita (1:5:25), daria origem à terça maior, demonstrando, assim, a gênese dos intervalos no sistema tonal, sem qualquer valor funcional ou analítico. O segundo contexto foi apresentado no tratado Génération Harmonique, em que Rameau (1737, p. 145155) documentou o aparecimento das relações de terça cromática, afirmando que as mesmas dariam origem ao gênero melódico cromático, tendo sido esta sua primeira discussão acerca da movimentação da linha do baixo por terças. Neste tratado, Rameau incluiu as quatro variedades de terças diretas: maior, menor, ascendente e descendente; no entanto, ele considerava esses acordes alterados como dominantes secundárias, estabelecendo uma relação com a tônica, como se observa no Exemplo 1:

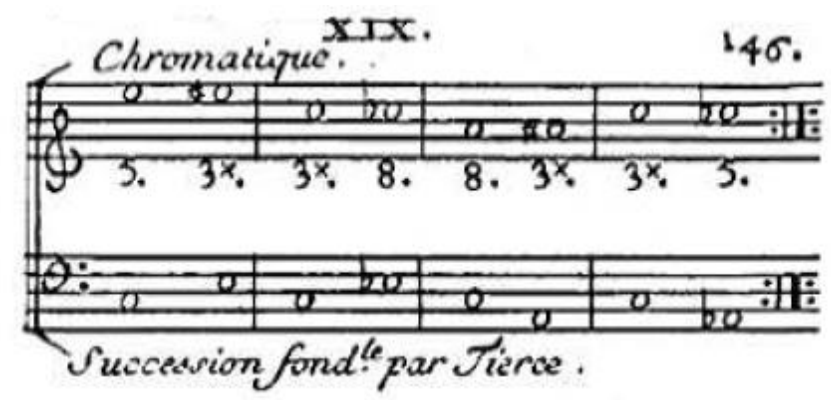

Exemplo 1. Relações de terça cromática na teoria de Rameau (1737, p.146)

Reicha (1818) considerava mediantes cromáticas como modulações obtidas sem a ocorrência de acordes intermediários. Ele reapresentou algumas ideias de Rameau, porém modificadas, em um formato mais adequado para a época. Ele manteve a relação de quinta de Rameau, mas admitia a expansão de 
materiais utilizados pelos compositores do período, abandonando a ideia de dissonância de sexta acrescentada.

Reicha adotou ainda a teoria de inversões e fundamentais no baixo, estabelecendo como intervalos apropriados para movimentação no baixo terças, quartas e quintas descendentes e suas inversões: sextas, quintas e quartas ascendentes. Afirmou também que a movimentação de dois acordes com relação intervalar de quinta descendente correspondia à força de uma lei da natureza, porquanto todo acorde dissonante deveria resolver desta maneira (Reicha 1818, p. 9, apud Kopp 2002, p. 39). De acordo com Reicha, a modulação para tonalidades próximas realizava-se sem o uso de acordes intermediários, ao passo que a modulação para tonalidades remotas utiliza acordes intermediários que intervêm nas áreas tonais. Estabeleceu ainda o paradigma de que o número de acordes intermediários requeridos para uma modulação direta corresponde às diferenças quantitativas em acidentes entre as armaduras de clave das duas tonalidades envolvidas, ou seja, a terça cromática que se move de Sol Maior para Mi Maior, onde a diferença entre as armaduras de clave é de três sustenidos, necessitaria de três acordes intermediários. Criou assim uma conexão entre seis tonalidades que constituem a base da progressão harmônica e da modulação, com possibilidade de movimento entre tonalidades que correspondem às tríades sobre o segundo, terceiro, quarto, quinto e sexto graus.

Weber, contemporâneo de Reicha, teórico funcionalista, utilizou numerais romanos para indicar os graus da escala (fundamentais dos acordes) e a natureza dos acordes sobre essas fundamentais. Estabeleceu a teoria de acordes e funções harmônicas, onde, em alguns pontos, opunha-se fortemente ao conceito de função harmônica de Hugo Riemann.

Em Versuch einer geordneten Theorie der Tonsetzkunst (1817-1821), Weber definiu sete harmonias fundamentais: tríades maiores, menores e diminutas e quatro tipos comuns de acordes de sétima. Desse material enumerou catorze acordes primários, tríades e acordes com sétima, localizados em cada grau da escala diatônica maior: I, IV e V seriam os acordes mais importantes de uma tonalidade, e as relações entre os acordes seriam obtidas entre esses três acordes principais e os acordes primários da tonalidade.

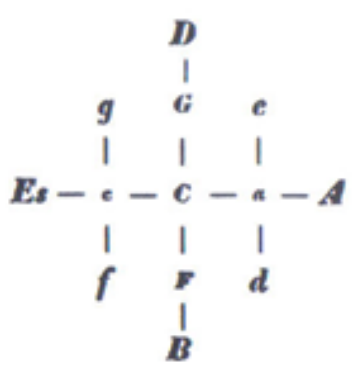

a) Tônica Maior

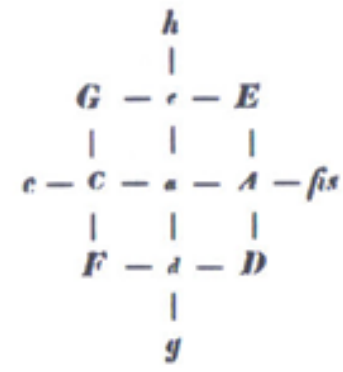

b) Tônica Menor

Exemplo 2 - Weber: relações próximas de uma tônica dada 
Ao discutir as progressões harmônicas, Weber expôs um argumento para mostrar a multiplicidade de diferentes progressões possíveis dentro de uma tonalidade e entre membros de diferentes tonalidades, afirmando que a relação mais estreita entre as tonalidades é a que liga as paralelas maior e menor, conforme se vê nos Exemplos 2 e 3.

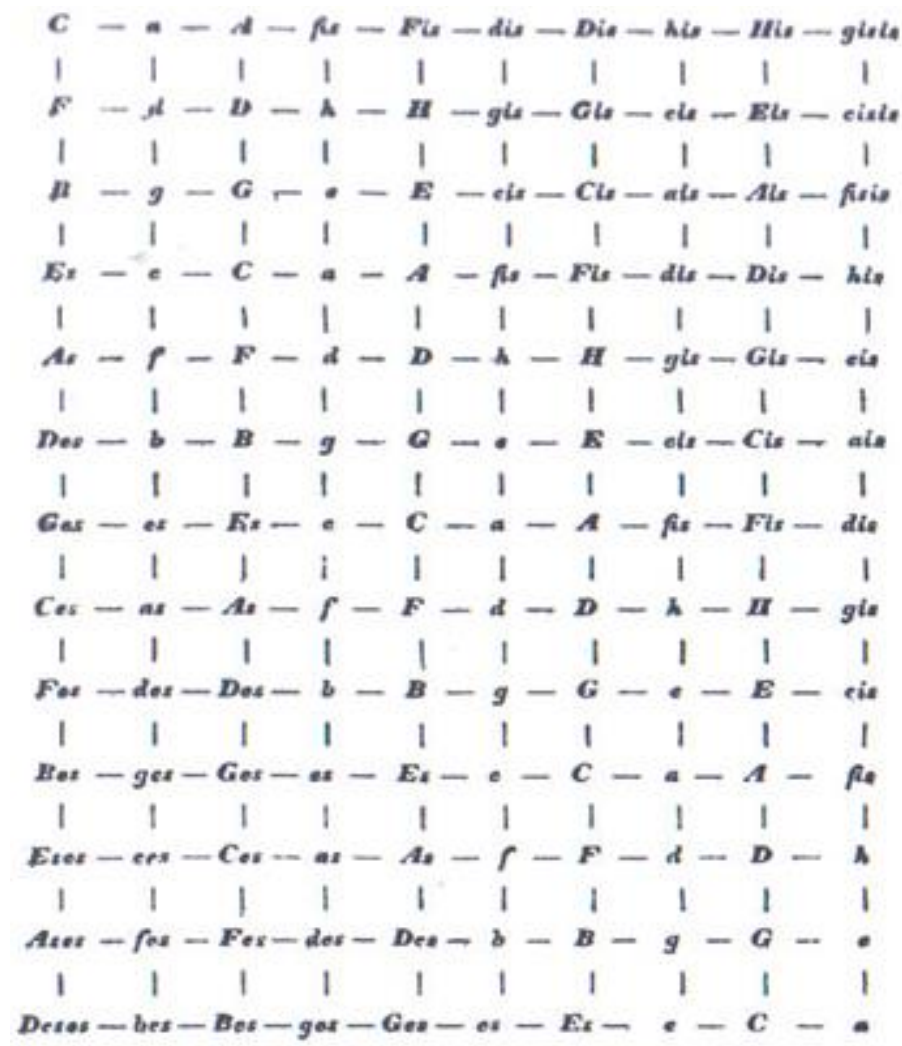

Exemplo 3 - Weber: Sistema de Relações entre as Tonalidades (Tonarten Verwandtschaften ou Mapa de Afinidades entre as Tonalidades)

Ao se examinar as propostas desses três teóricos, nota-se uma expansão gradual das possibilidades de relações entre os acordes e as tonalidades do sistema harmônico tonal, as quais teriam ainda ampliações consideráveis com as propostas de Riemann.

\section{A teoria dualista de Riemann e as relações entre os acordes}

Na maioria de seus diversos tratados de teoria musical, Riemann utiliza o conceito de dualismo que considera a existência e a causalidade eficiente da série harmônica nas formas ascendente e descendente. Esse conceito foi usado por outros autores anteriores, como Hauptmann, mas sem a mesma condição de premissa básica que adquiriu na teoria de Riemann. Por exemplo, em Riemann (1893, p. 6) é apresentada a formação dos acordes relacionando-os aos sons da 
série harmônica em movimentação ascendente e descendente. Desta forma, obtém-se o acorde maior e o acorde menor, denominados, respectivamente, de:

- Acorde de Harmonia Superior (Overclang) - Acorde Maior: combinação de uma nota (prime) com sua $3 \mathrm{M} \mathrm{e} 5 \mathrm{~J}$ ascendentes. A notação para este acorde considera como nota de origem sua nota mais grave, acrescentando-se à mesma o sinal "+". O acorde de Dó Maior, por exemplo, é representado por dó+.

- Acorde de Harmonia Inferior (Underclang) - Acorde menor: combinação de uma nota (prime) com sua $3 \mathrm{M}$ e $5 \mathrm{~J}$ descendentes. A notação para este acorde considera como nota de origem sua nota mais aguda, antecedendo-se à mesma o sinal "o". O acorde de lá menor, por exemplo, é representado por ${ }^{\circ} \mathrm{mi}$, como se observa no Exemplo 4.

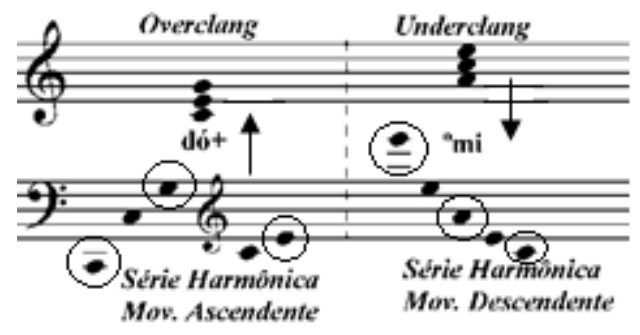

Exemplo 4 - Hugo Riemann: Acordes de harmonia superior e inferior

Ao elaborar um estudo sobre as relações harmônicas entre os acordes, inclusive aqueles alterados cromaticamente, Riemann considera os intervalos entre as fundamentais dos mesmos, sublinhando que acordes menores têm sua nota de origem simetricamente inversa ao acorde maior. Organiza, então, uma classificação de quatro relações - Marcha, Contramarcha, Câmbio e Contracâmbio (Riemann 2005, p. 101-103), as quais são resumidas na Tabela 1.

\begin{tabular}{|l|l|l|}
\hline \multicolumn{1}{|c|}{ Relação } & \multicolumn{1}{|c|}{ Estrutura da relação } & $\begin{array}{l}\text { Exemplos } \\
\text { Morcha } \\
\text { com movimentação }\end{array}$ \\
\hline Contra Marcha & $\begin{array}{l}\text { Acordes de mesma } \\
\text { modalidade (M-M/m-m), } \\
\text { com movimentação }\end{array}$ \\
\hline Câmbio & $\begin{array}{l}\text { Acordes de modalidades } \\
\text { diferentes (M-m/m-M), } \\
\text { com movimentação }\end{array}$ \\
\hline Contra-Câmbio & $\begin{array}{l}\text { Acordes de modalidades } \\
\text { diferentes (M-m/m-M), } \\
\text { com movimentação }\end{array}$ \\
\hline
\end{tabular}

Tabela 1 - Relações entre as fundamentais dos acordes (Riemann 2005, p. 101) 
Para Riemann, a noção moderna de tonalidade não estava atrelada à escala. Uma tonalidade poderia abranger também acordes que empregavam notas não contidas na escala, as quais seriam entendidas como relacionadas à tônica e daí receberiam seu significado singular.

Seria assim para todos os acordes de relação intervalar de terça maior com a tônica (por exemplo, Mi M e Láb M em Dó M) e acordes de relação intervalar de terça menor com a tônica (por exemplo, Mib M e Lá M em Dó M). Desta forma, Riemann identificou e legitimou as mediantes cromáticas como um grupo de acordes fora do conjunto diatônico, mas que poderiam ser ouvidos em relação direta com a tônica. Ficava, assim, claramente definido um espaço tonal incluindo relações cromáticas, diatônicas e diretas.

Publicações relevantes da década de 1880 incluem dois tratados nos quais Riemann apresenta suas novas propostas: Skizze einer neuen Methode der Harmonielehre - Esboço de um Novo Método de Harmonia (1880) e Sistematische Modulationslehre - Teoria da Modulação Sistemática (1887), juntamente com duas publicações nas quais resume e desenvolve esses estudos: Allgemeine Musiklehre (Katechismus der Musik) - Teoria Geral da Música (Catecismo da Música) (1888) e Katechismus der Harmonielehre - Catecismo da Harmonia (1890), que contém várias discussões sobre as relações de terça cromática.

À época de Skizze einer neuen Methode der Harmonielehre (Riemann 1880), a teoria de Riemann era fortemente embasada no princípio dualístico, partindo da natureza dupla do maior e do menor. A maior inovação desse tratado é a apresentação de um sistema de classificação que pretendia cobrir todos os tipos de progressão de acordes de acordo com a direção dos intervalos entre suas fundamentais. No Katechismus, a principal novidade é a introdução do conceito de função harmônica. Esses dois conceitos são aspectos separados e independentes na teoria harmônica de Riemann, tendo significados distintos. Essas alternâncias conceituais devem ser entendidas no contexto da expansão das estruturas harmônicas do repertório da segunda metade do século XIX, no qual a prática da harmonia se torna consideravelmente mais cromática ediversifica da.

Nota-se que Riemann almejava uma teoria da harmonia suficientem ente abrangente para descrever todas as possibilidades de desdobramento da tonalidade, enquanto, ao mesmo tempo, cuidava para especificar o lugar do cromatismo dentro do sistema tonal como um todo, preservando a essência da sua lógica.

Riemann organizou seu sistema de intervalos entre fundamentais em dois formatos: o primeiro apresentava várias progressões de intervalos entre as fundamentais, tal como ocorrem em contextos diatônicos (dentro da tonalidade), às vezes envolvendo a tônica, às vezes não. O segundo listava sistematicamente uma gama completa de progressões pelo âmbito intervalar, todas relacionadas ao mesmo acorde de tônica. 
No primeiro caso, havia duas classes importantes de conexão: intervalos que conectavam acordes primários e intervalos associados aos acordes secundários, os quais se desdobravam em intervalos que ligavam um acorde primário e um acorde secundário e intervalos que uniam dois acordes secundários, como é mostrado na Tabela 2.

\begin{tabular}{|c|c|c|c|}
\hline Classe & $\begin{array}{l}\text { Relação intervalar entre } \\
\text { as fundamentais }\end{array}$ & Exemplos em Dó $\mathbf{M}$ & Exemplos em lá $\mathrm{m}$ \\
\hline \multirow{6}{*}{$\begin{array}{l}\text { Entre } \\
\text { acordes } \\
\text { primários }\end{array}$} & uníssono & $\mathrm{C}^{+}-{ }^{\circ} \mathrm{C}: \mathrm{Dó} \mathrm{M}-$ fá $\mathrm{m}$ & ${ }^{\circ} \mathrm{e}-\mathrm{e}+$ : lá $\mathrm{m}-\mathrm{Mi} \mathrm{M}$ \\
\hline & quinta justa ascendente & c+- g+: Dó M - Sol M & oe - oa: lá $\mathrm{m}$ - ré $\mathrm{m}$ \\
\hline & quinta justa descendente & c+ - f+: Dó M - Fá M & oe - ob: lá $\mathrm{m}-\mathrm{mi} \mathrm{m}$ \\
\hline & segunda maior ascendente & f+ - g+: Fá M - Sol M & ob - oa: mi m-rém \\
\hline & quinta justa ascendente & $\mathrm{f}+{ }^{\circ}{ }^{\circ} \mathrm{C}:$ Fá $\mathrm{M}-$ fá $\mathrm{m}$ & ob-e+: mi m-Mi M \\
\hline & quinta justa descendente & g+ - ${ }^{\circ} \mathrm{C}:$ Sol M - fá m & ${ }^{\circ} \mathrm{a}-\mathrm{e}+$ : ré $\mathrm{m}$ - Mi M \\
\hline \multirow{5}{*}{$\begin{array}{l}\text { Entre } \\
\text { acordes } \\
\text { primários e } \\
\text { secundários }\end{array}$} & terça maior ascendente & c+ - oe: Dó M - lá m & oe - c+: lá m-Dó M \\
\hline & terça menor descendente & c+ - oa: Dó M - rém & ${ }^{\circ} \mathrm{e}-\mathrm{g}+$ : lá $\mathrm{m}-\mathrm{Sol} \mathrm{M}$ \\
\hline & segunda menor descendente & c+ - ob: Dó M-mi m & oe - f+: lá $\mathrm{m}$ - Fá M \\
\hline & segunda maior descendente & oa - g+: ré $\mathrm{m}-\mathrm{Sol} \mathrm{M}$ & $\mathrm{g}^{+-}$oa: Sol M - ré m \\
\hline & $\begin{array}{l}\text { quarta aumentada } \\
\text { ascendente }\end{array}$ & f+- ob: Fá M - mi m & ob - f+: mi m - Fá M \\
\hline \multirow{3}{*}{$\begin{array}{l}\text { Entre } \\
\text { acordes } \\
\text { secundários }\end{array}$} & terça maior descendente & ${ }^{\circ} \mathrm{e}-{ }^{\circ} \mathrm{c}:$ lá $\mathrm{m}-$ fá $\mathrm{m}$ & c+-e+: Dó M - Mi M \\
\hline & terça menor ascendente & oa - ${ }^{\circ} \mathrm{C}:$ ré $\mathrm{m}-$ fá $\mathrm{m}$ & $\mathrm{g}^{+}-\mathrm{e}+\mathrm{Sol} \mathrm{M}-\mathrm{Mi} \mathrm{M}$ \\
\hline & segunda menor ascendente & ob - ${ }^{\circ} \mathrm{C}: \mathrm{mi} \mathrm{m}-$ fá $\mathrm{m}$ & $\mathrm{f}+-\mathrm{e}+$ : Fá $\mathrm{M}-\mathrm{Mi} \mathrm{M}$ \\
\hline
\end{tabular}

Tabela 2 -Principais relações de intervalos de fundamental no Skizze (Riemann 1880)

A essa altura Riemann já não faz mais nenhuma tentativa para caracterizar as mediantes como substitutas de tônica ou dominante. Em vez disso, ele afirmava, em termos claros que, como as dominantes, mediantes cromáticas são um tipo distinto de progressão que poderia representar uma relação direta e significativa com a tônica. Pouco tempo depois, dentro de seu sistema de relações de intervalos entre fundamentais, Riemann proporia uma expressão mais geral de suas idéias sobre as mediantes no Die Natur der Harmonik (Riemann 1882).

Porém do Katechismus (Riemann 1890) ele restringiu os saltos permitidos entre tonalidades a uma pequena lista de dez relações entre intervalos de fundamentais, agrupando tonalidades que podem ser diretamente relacionadas em modulação pela sucessão imediata (sem a mediação de suas tríades de tônica). Esta lista continha apenas relações de quinta, mudança de modo (paralelas e relativas), e as quatro relações de terças cromáticas.

\section{O Legado de Riemann e as Teorias de Lewin e Kopp}

Teóricos que estudaram a teoria de Riemann, chamados neo-riemannianos ou teóricos da transformação, têm projetado seus sistemas para explicar e aplicar 
no repertório altamente cromático da segunda metade do século XIX. Nesse processo, relações de terça e quinta constituem o assunto mais abordado.

O teórico David Lewin é considerado o pioneiro no contexto de um considerável trabalho no que diz respeito ao desenvolvimento de modelos de transformações de relações de acordes.

O ponto de partida do sistema de Lewin é um artigo de 1982, A Formal Theory of Generalized Tonal Functions (Uma Teoria Formal das Funções Tonais Generalizadas), onde ele descreve a formalização matemática de um tipo geral de sistema harmônico que denomina "sistema de Riemann".

Esse sistema de Riemann é definido por um intervalo de tônica, $T$, e dois intervalos básicos, $d$ e $m$, para dominante e mediante. Os intervalos $d$ e $m$ especificam uma distância dada em semitons da tônica até outra altura, e não precisam ter o mesmo valor de semitons de um caso específico para outro. Os três elementos fundamentais se combinam para formar a tríade de tônica $(T, T+m$, $T+d$ ). Tríades adicionais são construídas a partir dos intervalos básicos: a tríade de subdominante, por exemplo, seria: $(T-d, T-m, T)$.

Lewin propõe operações que transformam o sistema de Riemann, relacionando-o a outros. Por isso o sistema é dito transformacional. A primeira operação é SHIFT, que transpõe todos os elementos do sistema a uma distância fixa de terça - maior ou menor - à esquerda ou à direita de determinada altura. Portanto, SHIFT(2) move um sistema com a tônica Dó Maior duas "distâncias" à direita, trazendo Sol Maior como a nova tônica, a dominante do sistema original. SHIFT(-1) move o mesmo sistema uma "distância" para a esquerda, levando à nova tônica lá menor (Lewin chamava a relativa de submediante do sistema original, pois, em uma visão dualista, ela é simetricamente oposta à mediante), como se vê no Exemplo 6.

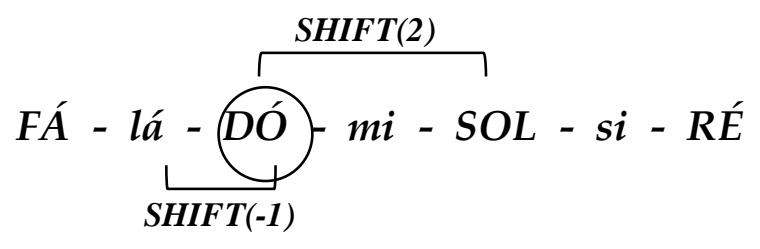

Exemplo 6 - Operações SHIFT +2 e -1 segundo Lewin

Dessa definição de Lewin resulta um grupo de quatro possibilidades de relações SHIFT com valores 2, 1, -1 e -2, chamadas DOM, MED, SUBM E SUBD, como mostra o Exemplo 7. 


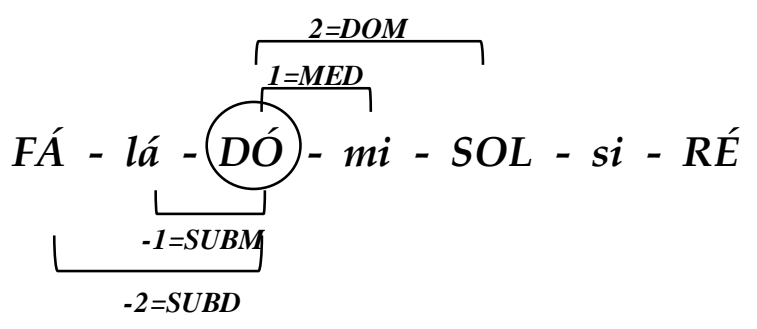

Exemplo 7 - As quatro relações SHIFT

Em seguida, Lewin estabelece um segundo grupo de três transformações, $I N V$, as quais mantêm duas notas em comum com a tríade, enquanto a terceira é a inversão do eixo formado pelas duas alturas constantes. Essas operações são dualistas, funcionando ascendentemente no modo maior e descendentemente no modo menor. Surgem, assim, as transformações TDINV (mudança de modo paralela), TMINV (mudança de modo relativa) e MDINV (Leittonwechsel, como Riemann havia chamado essa relação). Essas relações estão exemplificadas no Tabela 3. Posteriormente, Lewin renomeou TDINV, TMINV e MDINV como PAR, REL e LT.

\begin{tabular}{|c|c|c|c|c|}
\hline Transformação & \multicolumn{3}{|c|}{ Tríade } & Riemann \\
\hline \multirow{2}{*}{$\begin{array}{c}\text { TDINV } \\
\text { (ou } P A R \text { ) }\end{array}$} & \multirow[t]{2}{*}{ dó } & $m i$ & \multirow[t]{2}{*}{ sol } & \multirow[t]{2}{*}{$(\% /+)$} \\
\hline & & mib & & \\
\hline \multirow{2}{*}{$\begin{array}{c}\text { TMINV } \\
\text { (ou } R E L \text { ) }\end{array}$} & lá & \multirow[t]{2}{*}{$m i$} & \multirow[t]{2}{*}{ sol } & \multirow[t]{2}{*}{$(p)$} \\
\hline & dó & & & \\
\hline \multirow{2}{*}{$\begin{array}{l}\text { MDINV } \\
\text { (ou } L T \text { ) }\end{array}$} & \multirow[t]{2}{*}{ dó } & \multirow[t]{2}{*}{$m i$} & sol & \multirow[t]{2}{*}{$(</>)$} \\
\hline & & & $s i$ & \\
\hline
\end{tabular}

Tabela 3 - Segundo grupo de transformações de Lewin

Diversos outros autores como Hyer (1995) e Cohn (1996, 1997 e 1998) propuseram modificações e aprofundamentos dos sistemas transformacionais iniciados por Riemann e Lewin. Não é o caso de detalharmos aqui cada uma dessas propostas, pois utilizaremos uma outra proposta, a consolidada por David Kopp (2002) que, além do mais, faz uma detalhada revisão crítica das propostas anteriores para finalmente propor um sistema abrangente e elegante.

O sistema proposto por Kopp, denominado sistema de transformações cromáticas, fundamenta-se na tonalidade de notas comuns. Este sistema não considera a questão do dualismo, descrevendo os acordes maiores e menores a partir de sua fundamental na altura mais grave. No sistema de Kopp, as transformações são designadas em itálico, e as características gerais das transformações, que podem ocorrer nas fundamentais, terça ou quintas dos acordes, com ou sem mudança de modo, têm suas notações dadas na Tabela 4. 


\begin{tabular}{|c|c|c|c|}
\hline Intervalo & $\begin{array}{c}\text { Mesmo } \\
\text { modo }\end{array}$ & $\begin{array}{c}\text { Mudança de } \\
\text { modo }\end{array}$ & Observações \\
\hline Fundamental & $I$ & $P$ & $\begin{array}{l}\text { Nesse caso Kopp usa notações semelhantes } \\
\text { às do sistema de Lewin: IDENT preserva o } \\
\text { modo do acorde, e REL implica na alteração } \\
\text { da terça, convertendo a tríade maior em } \\
\text { menor ou vice versa. }\end{array}$ \\
\hline Terça & $M / m$ & $R / r$ & $\begin{array}{l}\text { M e m: correspondem, respectivamente, aos } \\
\text { intervalos de } 3 \mathrm{M} \text { e } 3 \mathrm{~m} \text {, no sentido } \\
\text { descendente. Caso ocorram no sentido } \\
\text { ascendente, acrescenta-se aos mesmos "-1". } \\
\mathbf{R} \text { e } \mathbf{r} \text { : correspondem, respectivamente, aos } \\
\text { intervalos de } 3 \mathrm{M} \text { e } 3 \mathrm{~m} \text {, nos sentidos } \\
\text { ascendente ou descendente. }\end{array}$ \\
\hline Quinta & $D$ & $F$ & $\begin{array}{l}\text { D e F : correspondem ao intervalo } \\
\text { descendente de 5J (com a diferença de que } \\
\text { no primeiro o modo é mantido e no } \\
\text { segundo, não). Para indicar sentido } \\
\text { ascendente, acrescenta-se "-1". }\end{array}$ \\
\hline
\end{tabular}

Tabela 4 - Características gerais das transformações de Kopp e suas notações

A transformação SLIDE ou S (Kopp 2002, p. 175) considera duas tríades de modos opostos que compartilham a nota da terça em torno da qual invertem os intervalos de terças maiores e menores, por exemplo, Ré Maior e Ré\# menor, que compartilham a nota Fá\#, enquanto as outras notas deslizam cromaticamente (Ré $\rightarrow$ Ré\# e Lá $\rightarrow$ Lá\#). Esta relação foi inicialmente reconhecida por Lewin que foi quem a nomeou. Representa a mais distante relação por notas comuns entre acordes: movimentação de fundamentais por um intervalo de semitom (no caso acima Ré $\rightarrow$ Ré\#) unindo tonalidades distantes por quatro acidentes, e com mudança de modo. A terça constante marca essa conexão harmônica. Tomando a tríade de Sol M como ponto de partida, o Exemplo 8 traz um resumo das transformações fundamentais de Kopp que geram tríades transformadas.

$\mathrm{Na}$ teoria de Kopp, algumas transformações são compostas, ou seja, consideram a ocorrência de um acorde intermediário. A diferença entre o grau ii em modo maior e o acorde de Napolitana é uma transformação Slide, ou S. Assim, enquanto a progressão ii-V é uma transformação do tipo $F$, a progressão $\mathrm{N}-\mathrm{V}$ é uma SF. Também é uma transformação composta outra progressão, que lembra a $S$, mas na qual ambos os acordes são maiores (por exemplo Dó $\mathrm{M} \rightarrow$ Réb $\mathrm{M}$ ). Esta conexão será representada pela transformação composta DM. No exemplo mencionado acima, utiliza-se, como ponte entre os dois acordes, o acorde intermediário Fá $M$. Desta forma obtém-se a progressão Dó $M \rightarrow F a ́$ $M \rightarrow$ Réb $M$, onde $D$ representa a transformação Dó $M \rightarrow$ Fá $M$ e $M$ representa Fá $M \rightarrow$ Réb $M$. 


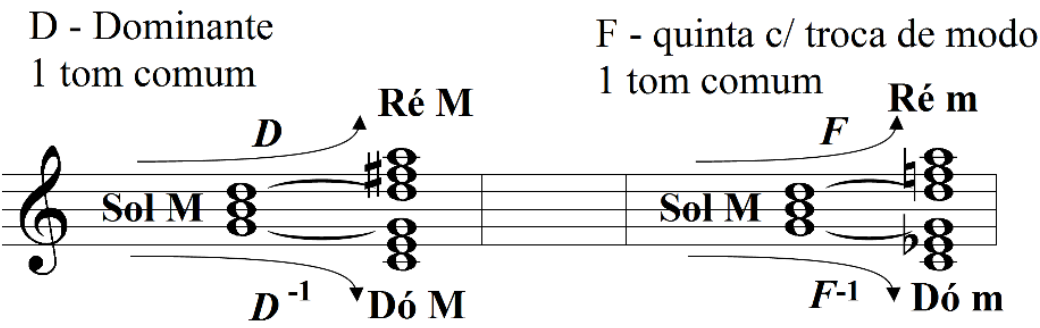

$\mathrm{M} / \mathrm{m}$ - Mediantes Cromáticas 1 tom comum

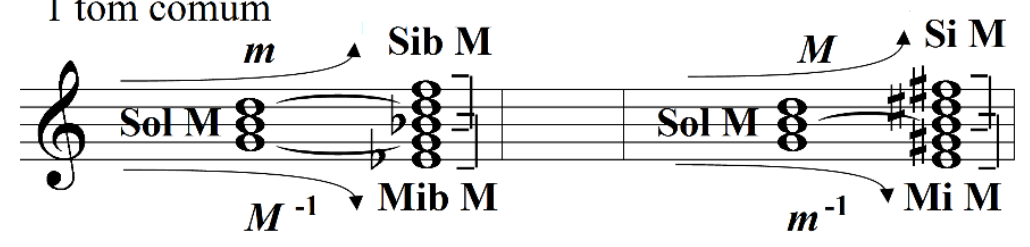

$\mathrm{R} / \mathrm{r}$ - Mediantes Relativas 2 tom comuns

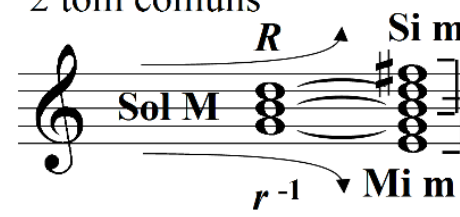

P - Paralela

2 tom comuns

- Identidade

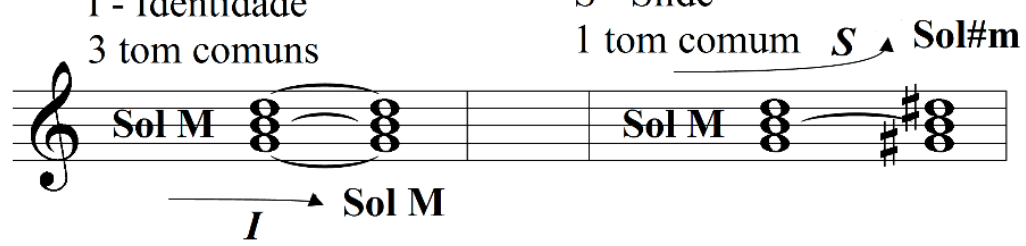

Exemplo 8 - Transformações cromáticas fundamentais de Kopp

A teoria da transformação formaliza o princípio que admite a ocorrência de um acorde mediador aproximando as progressões por movimentação de segunda (Kopp 2002, p.176). A progressão IV-V, por exemplo, é interpretada pela fórmula $D^{-2}$, representando um transformação da dominante inversa do acorde inicial para o acorde intermediário, seguido por outro, que vai do acorde intermediário ao acorde final.

Na tonalidade cromática, localizações não diatônicas dos intervalos entre fundamentais de certos acordes não implicam necessariamente em instabilida de, como é o caso do acorde de sexta aumentada (Kopp 2002, p.180). A movimentação de qualquer nota em uma progressão de acorde deve ser especificada matematicamente. A maior variedade de tétrades no sistema tonal, e a maior complexidade de suas interrelações (entre si e com as tríades), apresenta um desafio teórico que ainda está sendo estudado.

Para tal estudo, adota-se um tratamento mais informal da teoria harmônica, colocando as dissonâncias acrescentadas como uma transformação adicional adjunta às relações de tríade. Isto leva à conclusão, por analogia, que 
LFM $\rightarrow$ I e Ger ${ }^{+6} \rightarrow$ I são exemplos de $M^{-1}$ (LFM refere-se a Lower Flat Mediant, ou seja, acorde sobre o VI grau abaixado). A fórmula indicada para a resolução de uma sexta germânica em um acorde menor $6 / 4$ é $\boldsymbol{R}$. A resolução da sexta germânica direto para a dominante requer uma fórmula composta, $M^{-1} D^{-1}$ para o modo maior e $\boldsymbol{R F}^{-1}$ para o modo menor.

Algumas transformações compostas do sistema de Kopp são mostradas na Tabela 5 .

\begin{tabular}{|c|c|}
\hline$D^{-2}$ & 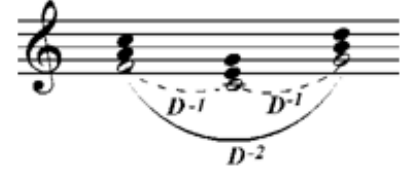 \\
\hline$D M$ & 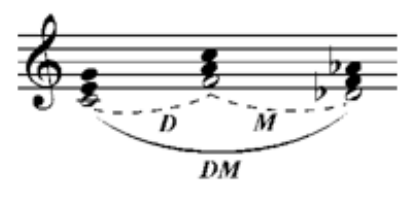 \\
\hline$M^{-1} D^{-t}$ & 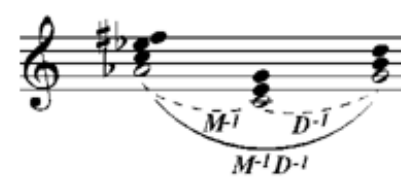 \\
\hline$R F^{-1}$ & 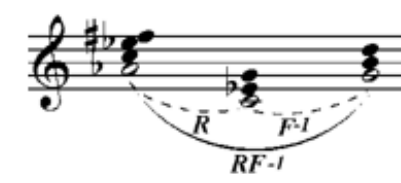 \\
\hline
\end{tabular}

Tabela 5 - Transformações compostas de Kopp

Não se pode contestar, por meio das teorias alternativas, como a de Kopp, apresentadas neste trabalho, a substancial importância do trabalho seminal de Riemann ao organizar um amplo sistema de notação para as relações entre as fundamentais dos acordes, que se constitui em uma ferramenta eficiente para a análise de textos musicais que contenham expansão harmônica. O que dificulta, talvez, a aplicação direta da teoria original riemanniana, seja a questão do dualismo harmônico, que obscurece a clareza na notação de relações entre as fundamentais dos acordes; e representa, para um trabalho de análise, uma tarefa árdua com resultados insatisfatórios em termos de visualização imediata dos resultados. Conclui-se, pois, que as propostas dos neo-riemannianos vieram contribuir de forma efetiva para uma melhor compreensão da teoria de Riemann. 


\section{Artémis - Cena I de Nepomuceno: Uma proposta de análise segundo o Sistema de Transformações Cromáticas}

A ópera Artémis, de Alberto Nepomuceno, apresenta-se em seis seções: Introdução, Cena I, Cena II, Interlúdio, Cena III e Cena IV.

Para este estudo de análise utilizou-se a partitura de redução para piano e optou-se por analisar a Cena I, 2ª seção da peça, que vai dos compassos 141 a 292. A divisão da seção em vários fragmentos foi orientada pelas variações de textura.

No Exemplo 9 apresentamos uma redução da estrutura harmônica do primeiro fragmento da Cena I, (compassos 141 a 152), com a notação da nossa proposta de análise transformacional.

A estrutura harmônica desse fragmento caminha de Sol M para Mib M/m, desenhando, portanto, uma relação de terça cromática.

Nota-se, neste trecho, uma clara ênfase nas relações de quinta (ascendente e descendente) em torno de Sol: Sol-Ré-Sol-Dó-Sol, que equivalem a relações funcionais de uma Tônica de Dó $\mathrm{M}$ com várias versões da Dominante Sol M (e ainda com uma passagem pela Dominante da Dominante Ré M). No final da passagem é que ocorre a primeira transformação cromática significante, qual seja, a transformação da tonalidade de Dó M para Mib M/m.

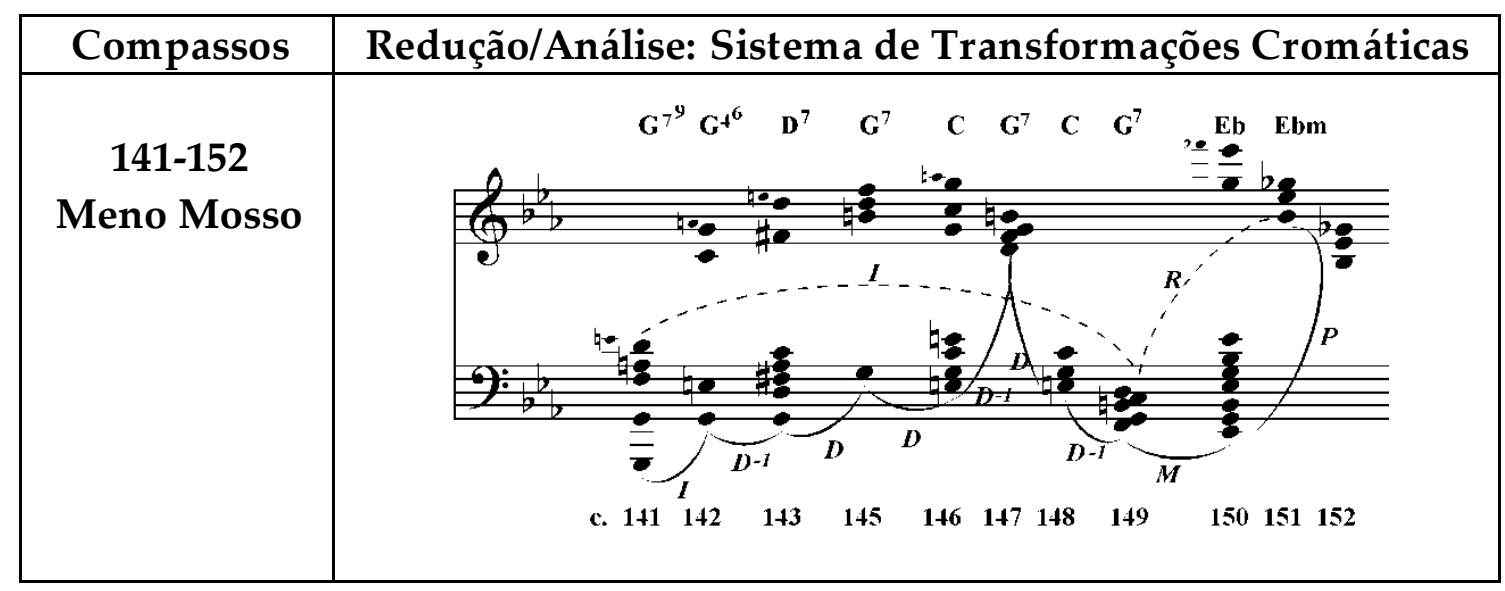

Exemplo 9 - Artémis, (c. 141-152): redução e análise segundo o sistema de Kopp

No segundo segmento, que vai dos compassos 153 a 168, observa-se um predomínio de relações de quinta, com transformações $\mathbf{F}$ e $\mathbf{D}$, embora também ocorram relações de terça, $\mathrm{M} / \mathrm{m}$, cuja estrutura é formada pelos acordes Mib $\mathrm{M}$, Si M7 , Dó\# M Mi M, como se vê no Exemplo 10. 


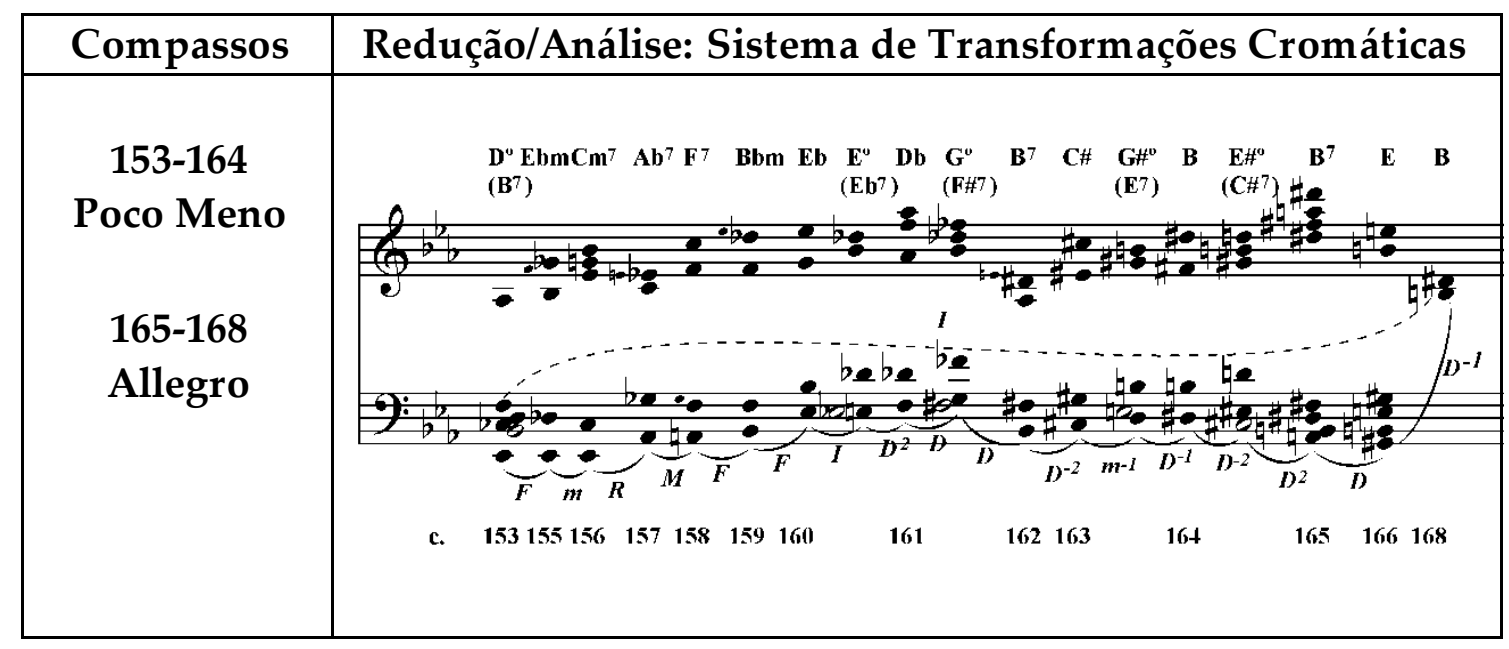

Exemplo 10 - Artémis, (c. 153-168): redução e análise segundo o sistema de Kopp

O terceiro fragmento (compassos 169-186) apresenta um prolongamento da harmonia de Sol $\mathrm{M}$, onde a sequência de acordes é Sol M7 , Mi M/9 $\mathrm{Lá}^{7} \mathrm{M}^{7}$, RébMํㄴ Lá $^{7}$, Sol M7 , conforme mostra o Exemplo 11.

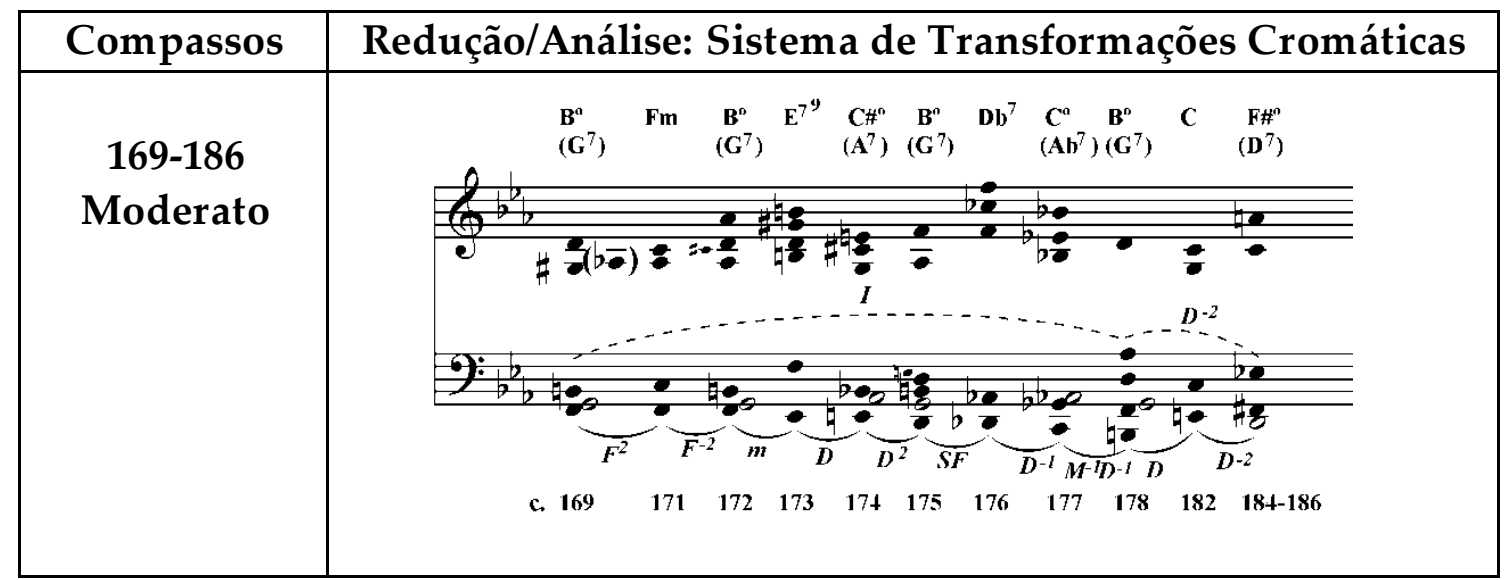

Exemplo 11 - Artémis, (c. 169-186): redução e análise segundo o sistema de Kopp

No quarto excerto, que se estende dos compassos 187 a 195, observa-se uma relação composta: $\mathbf{D M}$, onde Sol $\mathrm{M} \rightarrow$ Dó $\mathrm{M}$ (acorde intermediário) corresponde à transformação $\mathrm{D}$ e Dó $\mathrm{M} \rightarrow$ Láb $\mathrm{M}$ se refere à transformação $\mathbf{M}$, conforme mostra o Exemplo 12. 


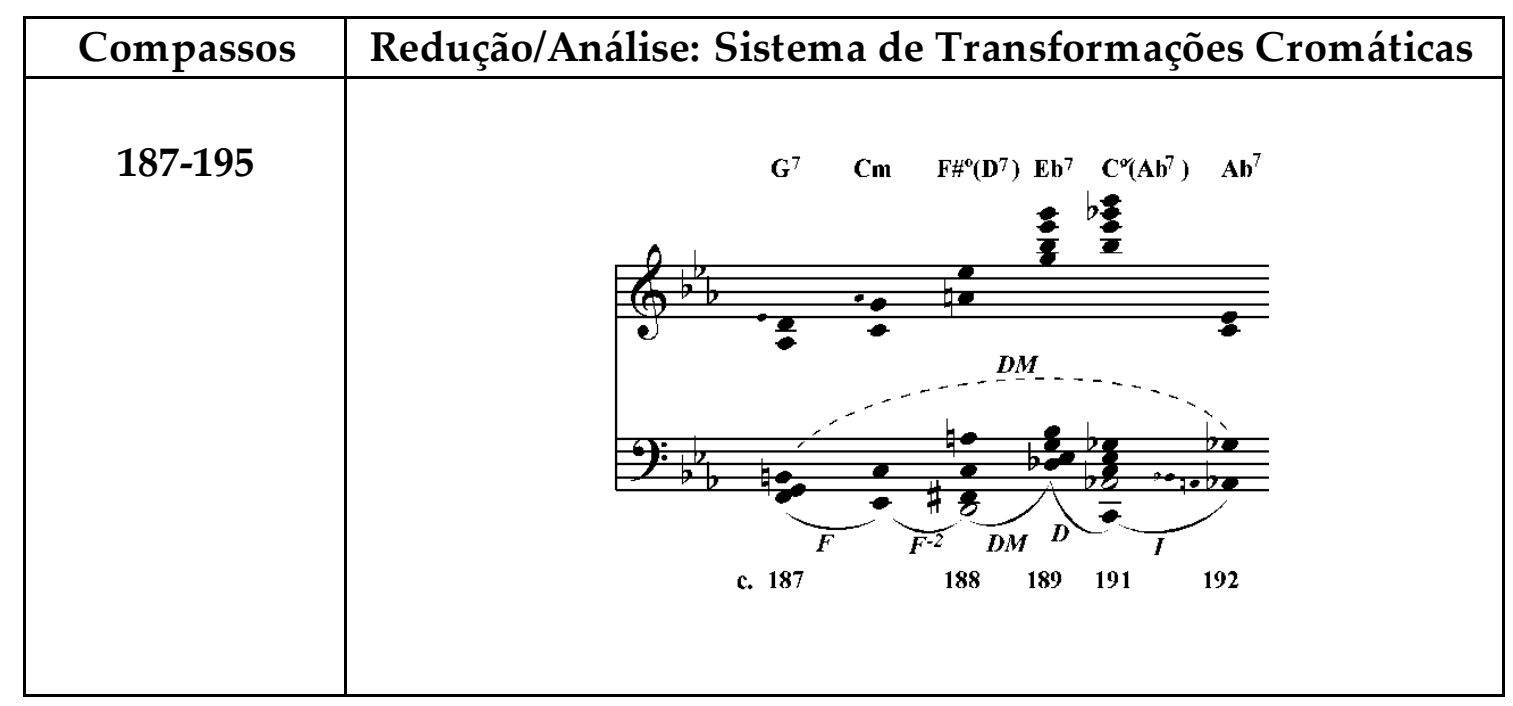

Exemplo 12 - Artémis, (c. 187-195): redução e análise segundo o sistema de Kopp

No quinto fragmento (compassos 196 a 207), predominam relações de quinta, com a harmonia girando em torno de Réb $\mathrm{M}$ e Láb $\mathrm{M}^{7}$, concluindo com um acorde de $\mathrm{Si}^{\mathrm{o}}$, aqui considerado $\mathrm{Sib} \mathrm{M}^{7}$, visto ser Mib $\mathrm{Mo}$ primeiro acorde do próximo segmento. Observe-se essa análise no Exemplo 13.

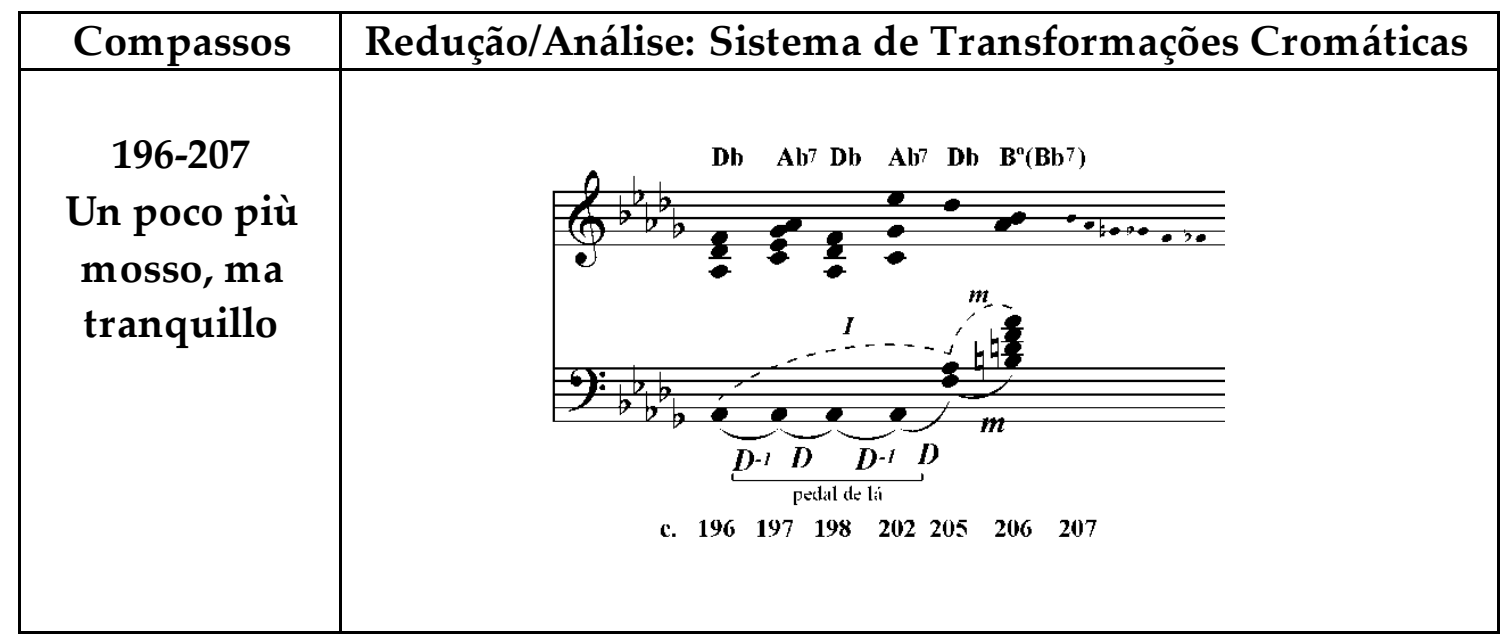

Exemplo 13 - Artémis, (c. 196-207): redução e análise segundo o sistema de Kopp

No sexto excerto, que engloba os compassos 208 a 252, ocorrem relações compostas: DR - D de Mib $\mathrm{m}$ a Láb $\mathrm{m}$ (= Sol\# $\mathrm{m})$ e $\mathbf{R}$ de Láb $\mathrm{m}$ a Mi M. As transformações $\mathbf{D}^{-1} \mathbf{M}^{-1}$ e $\mathbf{D}^{-1}$ se dão nas passagens das harmonias de Mi M a Si M e a transformação $\mathbf{M}^{-1}$ de Si M a Mib M (= Ré\# M). O acorde de Sio (Si diminuto) é considerado em dois formatos, para dar sentido ao contexto harmônico. Há um prolongamento da harmonia de $\mathrm{Mib} \mathrm{M} / \mathrm{m}$, que se conecta a Mi m por meio do acorde de Sol $\mathrm{M}^{7}$, portanto, por relações de terça (Mib M/m - Sol $\mathrm{M}^{7}$ - Mi m), conforme mostra o Exemplo 14. 


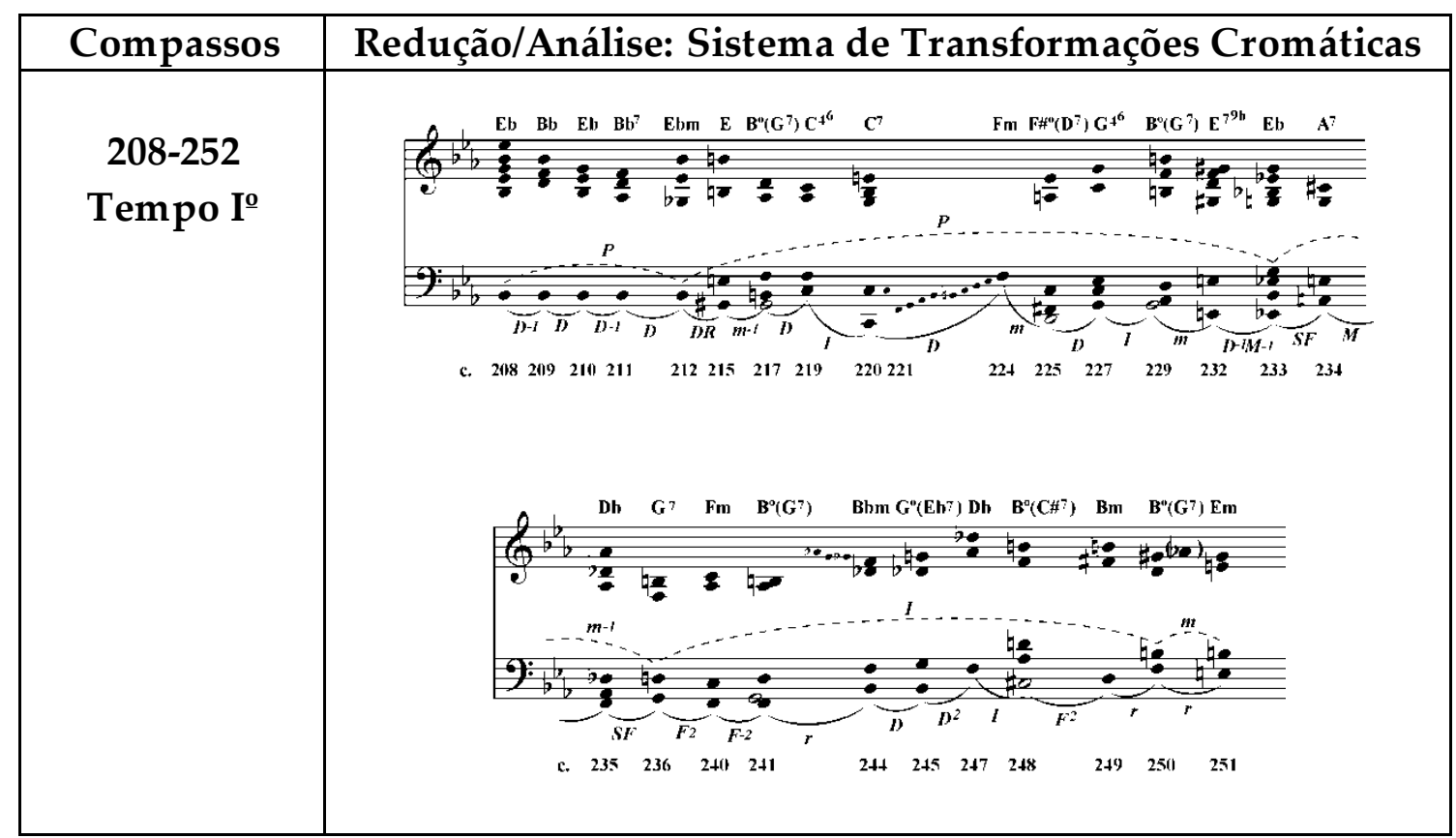

Exemplo 14 - Artémis, (c. 208-252): redução e análise segundo o sistema de Kopp

No sétimo segmento, entre os compassos 253 e 264, nota-se apenas intervalos de quinta entre as fundamentais dos acordes. Há um prolongamento da harmonia de Lá $m$, que chega a Fá\# $M$, portanto realizando uma transformação $r$, como se vê no Exemplo 15 .

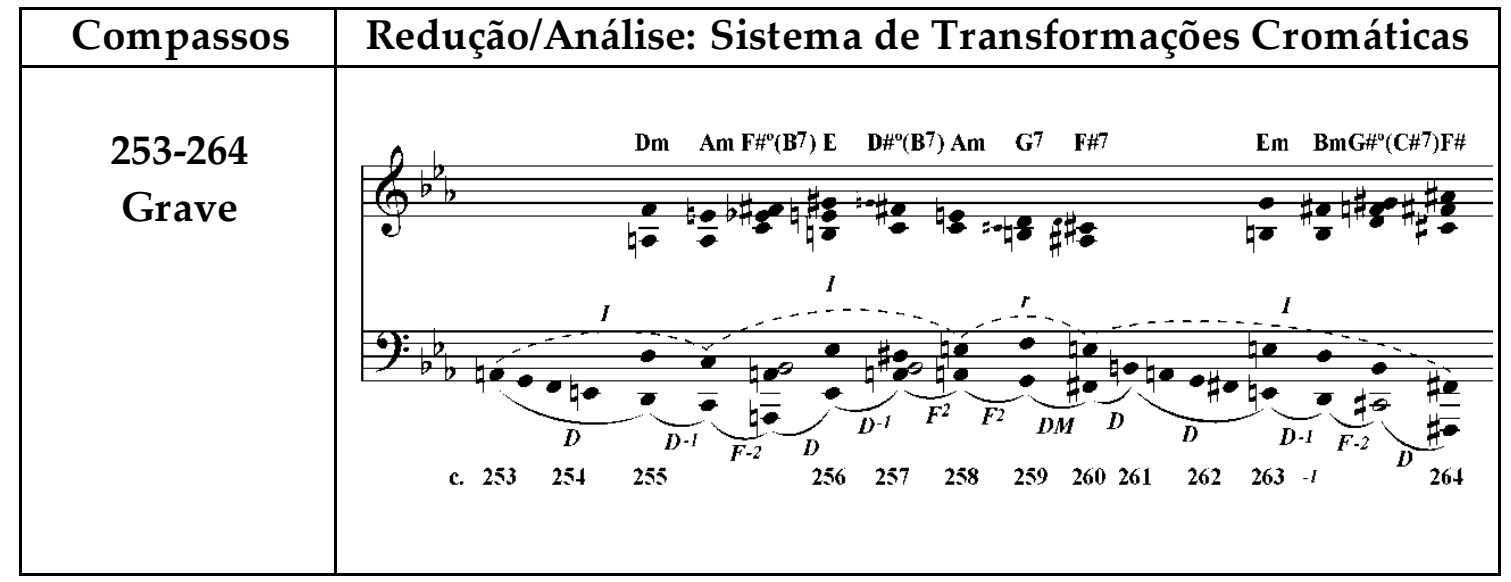

Exemplo 15 - Artémis, (c. 253-264): redução e análise segundo o sistema de Kopp

Nota-se um prolongamento da harmonia de $\mathrm{Mi}+/ \mathrm{MiM}$ no oitavo fragmento, que se apresenta entre os compassos 265 e 274, caminhando para a conclusão no acorde de Sol $\mathrm{M}^{7}$, portanto em uma relação de terça, transformação $\mathbf{M}^{-1}$, tal como mostra o Exemplo 16. 


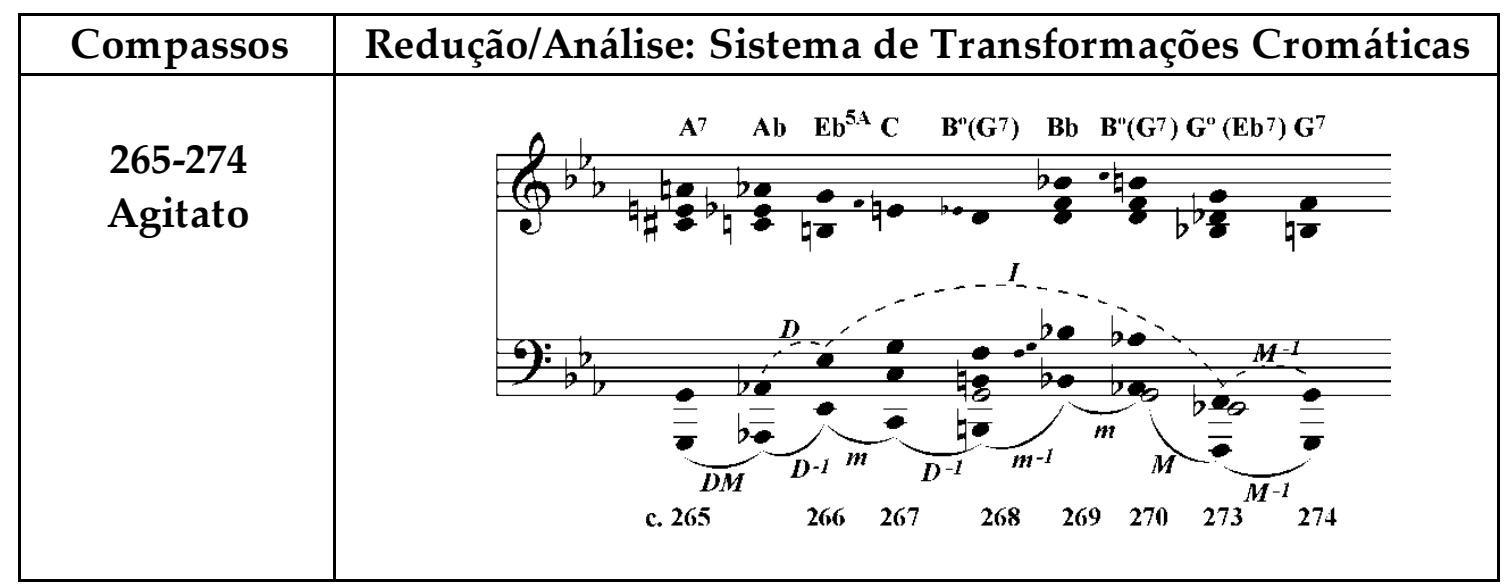

Exemplo 16 - Artémis, (c. 265-274): redução e análise segundo o sistema de Kopp

No último fragmento da Cena I, compassos 275 a 292, a harmonia caminha de Fá m para Láb $\mathrm{M}^{7}$, estabelecendo uma transformação $\mathbf{r}$, a qual se segue uma movimentação cromática (Láb $\mathrm{M}^{7}$ - Lá $\mathrm{M}^{7}$ ), transformação DM. Isso está demonstrado no Exemplo 17.

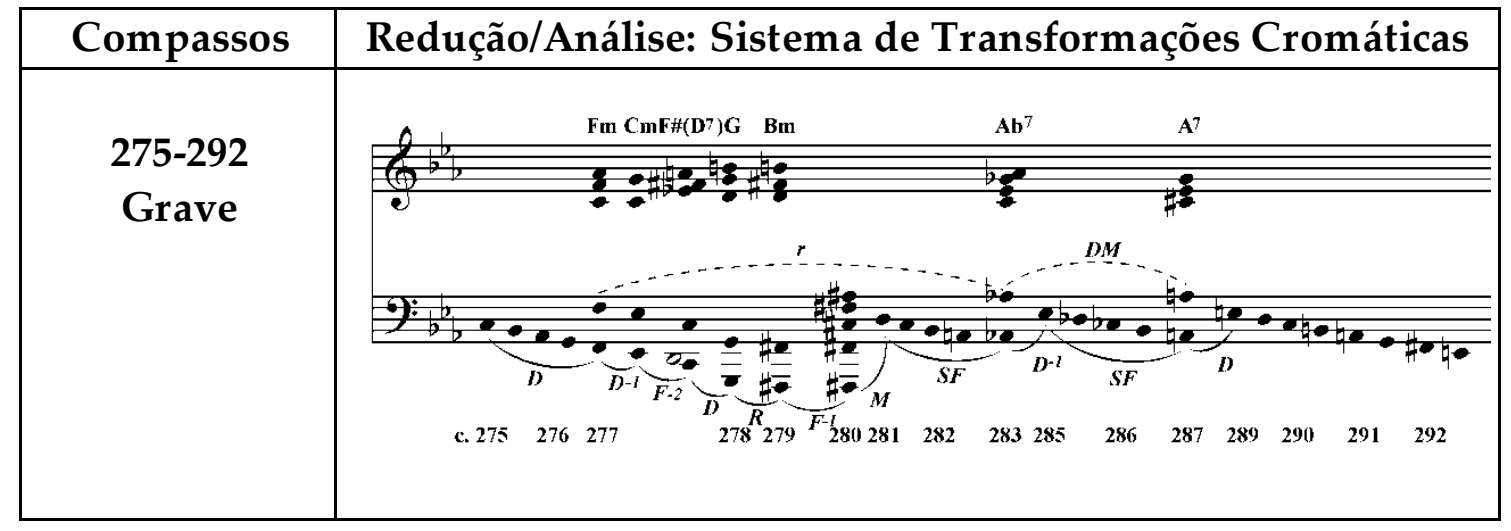

Exemplo 17 - Artémis, (c. 275-292): redução e análise segundo o sistema de Kopp

\section{Conclusões}

Com base na análise apresentada nos Exemplos 9 a 17, elabora-se um resumo apontando as principais transformações cromáticas que ocorrem na Cena I, como mostra o Exemplo 18.

Nota-se um predomínio das transformações cromáticas que caracterizam relações intervalares de terça e quinta, e um abundante emprego de cromatismo. 


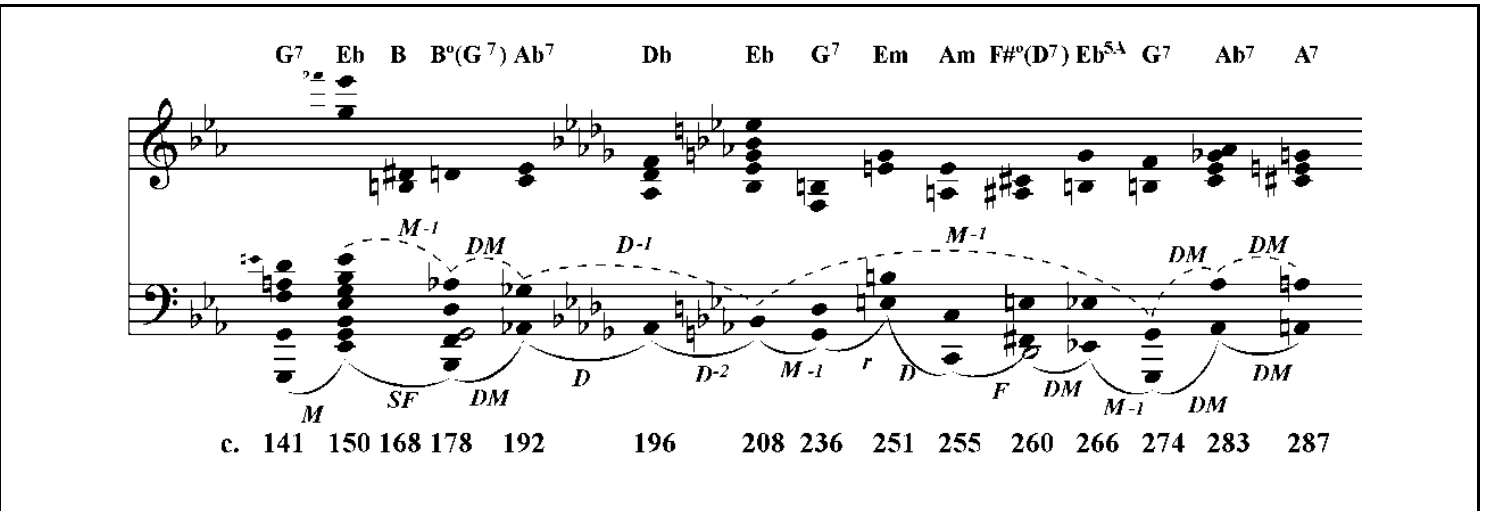

Exemplo 18 - Artémis, (c. 141-292): Resumo da estrutura harmônica

Indicando apenas as tríades principais desta redução, desta vez sem as extensões, verifica-se que esta seção da peça estrutura-se na sequência de acordes Mib M, Sol M, Láb Me Lá M, correspondendo, respectivamente, às funções T, D, $\mathbf{S}$ e $\mathbf{( N )}$ s, como se pode observar no Exemplo 19.

\begin{tabular}{|c|c|}
\hline $\begin{array}{l}\text { Resumo da estrutura } \\
\text { harmônica }\end{array}$ & 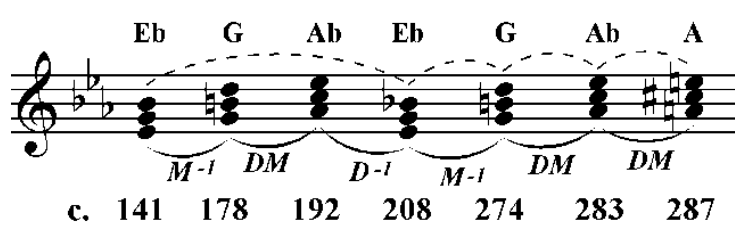 \\
\hline Indicação de funções & 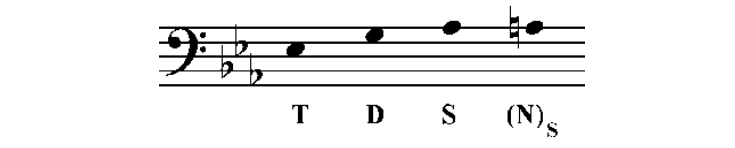 \\
\hline
\end{tabular}

Exemplo 19-Artémis, (c. 141-292): Tríades que compõem a estrutura harmônica com indicação de suas funções

Esta estrutura, dentro da proposta neo-riemanniana de Kopp, organizase em dois formatos: um diagrama de rede ou de conexões, e a representação dessas transformações cromáticas no Tonnetz elaborado por Riemann, conforme se aponta no Exemplo 20. 


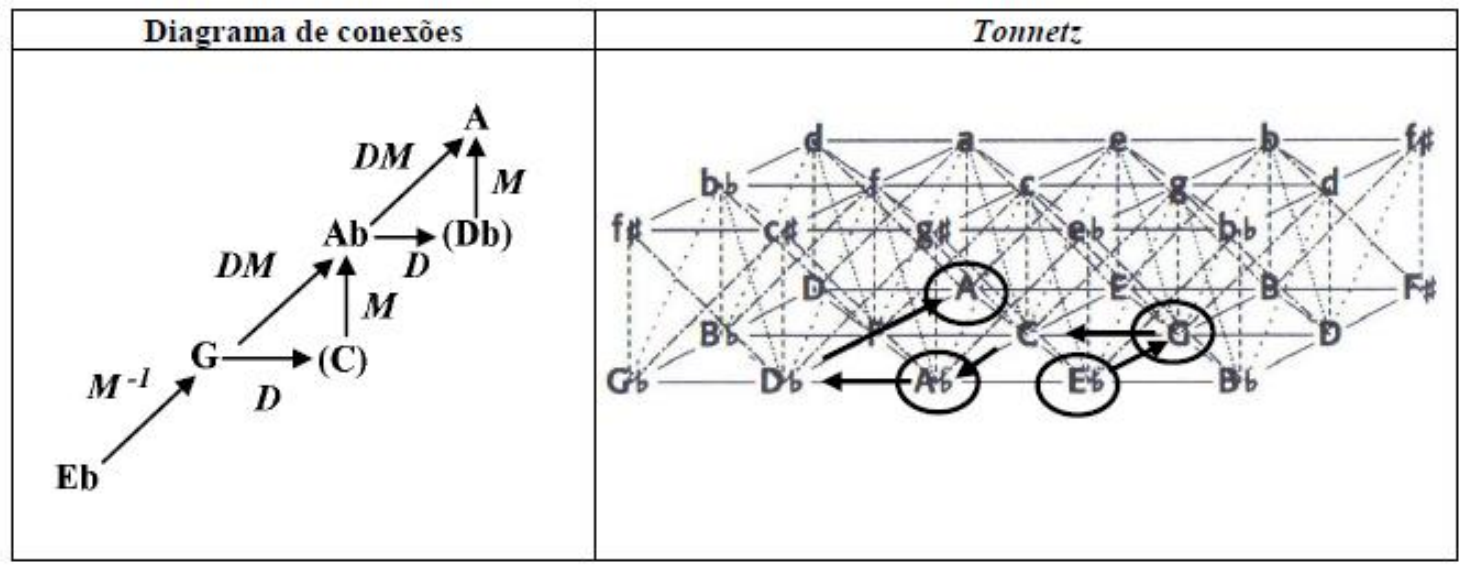

Exemplo 20 - Artémis, (c. 141-292): Diagrama de Conexões. Tonnetz.

A análise aponta que o centro tonal desta seção é Mib. Há um intenso uso de cromatismo, o que legitima o emprego desta ferramenta analítica.

O resultado final, apresentado no Exemplo 18, não corresponde a uma tríade, arpejo ou escala diatônica, indicando que o uso desta proposta analítica não nos retornaria um fechamento tonal satisfatório neste processo.

O resumo estrutural da Cena I compreende a sequência Mib $\rightarrow$ Sol $\rightarrow$ Láb $\rightarrow$ Lá, ou seja, um intervalo de terça seguido de uma movimentação cromática. O âmbito desta sequência, Mib - Lá, representa a maior distância que há entre duas alturas: o trítono. Há, portanto, as antípodas Mib - Lá nas extremidades de uma sucessão que compreende um intervalo de terça e um cromatismo.

Na ordem Mib-Sol-Láb-Lá, o acorde de Sol M corresponde à função de dominante. Segundo o sistema de Kopp, cada mediante cromática apresenta um semitom relacionado a uma nota específica, que indicará uma progressão de Dominante ou de Subdominante. No caso do acorde de Sol M (mediante superior sustenizada), a nota comum com o acorde de tônica é a fundamental, tal como ocorre com acorde de dominante do tom (Sib Maior - Mib Maior, em Mib Maior). A relação de terça descendente (Sol - Mi) difere da relação de quinta descenden te (Sib - Mib), e a terça do acorde de Sol M altera a fundamental do acorde de dominante do tom (Sib - Si natural, em Mib M), conferindo-lhe a função de Dominante.

Desta forma, estrutura-se uma cadência plagal, uma vez que a conclusão dá-se em dois acordes de Subdominante (S - Ns).

Ressalte-se aqui, que a expansão do sistema tonal, no século XIX, ocasionou um uso mais estendido do acorde de Subdominante, que adquiriu maior autonomia em sequências estruturais, bem como, segundo Stein (1985, p. 19-20), um status equivalente ao da dominante no período clássico.

A movimentação cromática Sol - Láb - Lá, confere ao contexto harmônico um caráter de unidade e, agregado a Mib, fecha um ciclo: os acordes de Mib Maior ${ }^{7}$ e Lá Maior ${ }^{7}$, além de guardarem a distância de um trítono entre as suas 
fundamentais, têm, por afinidade, o mesmo trítono, por enarmonia. Portanto, o trítono é um fator de unidade nesta seção, como mostra o Exemplo 21.

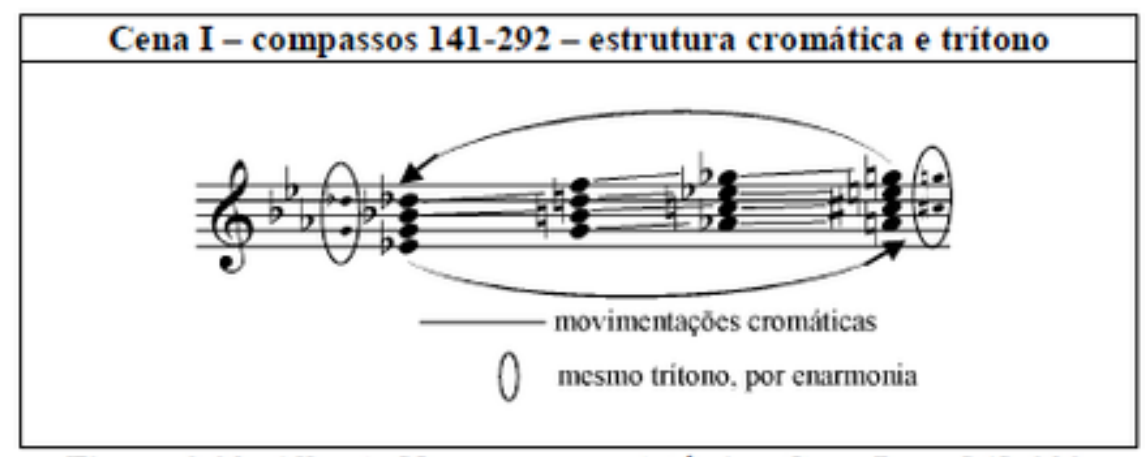

Exemplo 21 - Artémis, (c. 141-292): Ciclo de acordes com estrutura cromática e trítono.

Conclui-se, ratificando a questão da coerência e unidade desta seção, que apesar de empregar acordes alterados e realizar uma considerável expansão da tonalidade, a estrutura harmônica demonstra estar ainda atrelada a relações subordinadas ao sistema tonal e, nesse sentido, a obra tem o cuidado de organizar um processo lógico o bastante para não se desassociar do sistema tonal.

\section{Referências}

1. Cohn, Richard. 1996. Maximally Smooth Cycles, Hexatonic Systems, and the Analysis of Late Romantic Triad Progressions. Music Analysis, vol.15, n¹, p.9-40.

2 . 1997. Neo-Riemannian Operations, Parsimonious Trichords, and their "Tonnetz" Representations. Journal of Music Theory, vol. 42, n 1, p. 166.

3. 1998. Introduction to Neo-Riemannian Theory: A Survey and a Historical Perspective. Journal of Music Theory, vol. 42, n 2, p. 167-179.

4. Hyer, Brian. 1995. Reimag(in)ing Riemann. Journal of Music Theory, vol. 39, $\mathrm{n}^{\circ}$ 1, p. 101-138.

5. Kopp, David. 2002. Chromatic Transformations in Nineteenth-Century Music. Cambridge: Cambridge University Press. 
TADDEI, Rita de Cássia. 2016. Uma Análise Neoriemanniana da Primeira Cena do Artémis de Nepomuceno. MUSICA THEORICA. Salvador: TeMA, 201618, p.164-185.

6. Lewin, David. 1982. A Formal Theory of Generalized Tonal Functions. Journal of Music Theory, Vol. 26, No. 1, p. 23-60.

7. Rameau, Jean-Philippe. 1737. Génération Harmonique, ou Traité de musique theorique et pratique. Paris: Praut fils.

8. Reicha, Anton. 1818. Cours de Composition Musicale, ou Traité Complet et Raisonné d'Harmonie Pratique. Paris: Gambaro.

9. Riemann, Hugo. 1880. Skizze einer neuen Methode der Harmonielehre. Leipzig: Breitkopf \& Hartel.

10. 1882. Die Natur der Harmonik. Leipzig: Breitkopf \& Hartel.

11. 1887. Sistematische Modulationslehre als Grundlage der Musikalischen Formenlehre. Hamburgo: J. F. Richter.

12. 1888. Allgemeine Musiklehre (Katechismus der Musik). Berlim: Max Hesse.

13. 1890. Katechismus der Harmonielehre. Berlim: Max Hesse.

14. 2005. Teoria General de la Musica. Barcelona: Idea Books.

15. Stein, Deborah J. 1985. Hugo Wolf's Lieder and Extensions of Tonality. Ann Arbor: UMI Research Press.

16. Weber, Gottfried. 1817-1821. Versuch einer geordneten Theorie der Tonsetzkunst, vols. I-II. Mainz: B. Schott's Söhne. 